\title{
LH-Moments of the Wakeby Distribution Applied to Extreme Rainfall in Thailand
}

\author{
Busababodhin Piyapatr ${ }^{\mathrm{a}}$, Chiangpradit Monchaya ${ }^{\mathrm{a}}$, Phoophiwfa Tossapol ${ }^{\mathrm{a}}$, Jeong- \\ Soo Park ${ }^{\mathrm{b}}$, Do-ove Manoon ${ }^{\mathrm{c}}$, Guayjarernpanishk Pannarat ${ }^{\mathrm{d},{ }^{*}}$ \\ ${ }^{a} A p p l i e d$ Statistics Research Unit, Department of Mathematics, Mahasarakham \\ University, 44150 Maha Sarakham, Thailand; b Department of Statistics, Chonnam \\ National University, 500-757 Gwangju, South Korea; 'Upper North-Eastern Region \\ Meteorological Center, 41000 Khon Kean, Thailand; dFaculty of Interdisciplinary \\ Studies, Nong Khai Campus, Khon Kaen University, 43000 Nong Khai, Thailand
}

*For correspondence: panngu@kku.ac.th

Received: 09 Sep 2020 Accepted: 13 Mar 2021

(C) Copyright Piyapatr et al. This article is distributed under the terms of the Creative Commons Attribution License, which permits unrestricted use and redistribution provided that the original author and source are credited.
Abstract This article applies the Wakeby distribution (WAD) with high-order L-moments estimates (LH-moments) to annual extreme rainfall data obtained from 99 gauge stations in Thailand. The objective of this study is to investigate appropriate quantile estimates and return levels for several return periods, $2,5,10,25$, and 50 years. The $95 \%$ confidence intervals for the quantiles determined from the WAD are derived using the bootstrap technique. Isopluvial maps of estimated design values that correspond to selected return periods are presented. The LHmoments results are better than estimates from the more primitive L-moments method for a large majority of the stations considered.

Keywords: L-Moments, LH-Moments, Wakeby Distribution, Higher-Order Statistics, Bootstrap Resampling.

\section{Introduction}

The statistical modelling of extreme rainfall is important in the design of water-related structures such as agriculture. More generally, it provides us an information about weather modification and monitoring climate change (Huff and Angel, 1992). In particular, hydro-meteorologists can fit various statistical frequency distributions to historical rainfall data in order to estimate the magnitude of maximum rainfall at various recurrent intervals.

The rainfall between the months of August to October in Thailand is the time intereval that we are interested in this article. As elsewhere, extreme rainfall events can become natural disasters in Thailand, contributing to crop losses or property damage and general human misery (Deka et al., 2009). Khamkong (2012) and Khongthip et al. (2013) have previously modelled annual monthly maximum rainfalls in upper northern Thailand via generalised extreme value distributions (GEVD), Keawmun et al. (2015a), Keawmun et al. (2015b), and Busababodhin et al. (2015a) likewise modelled annual daily and monthly maximum rainfalls in northeastern Thailand.

To the best of our knowledge, no study has yet employed any other statistical distribution to model rainfall data in Thailand. However, empirical evidence related to the condition of separation (Matalas et al., 1975) 
suggests that flood distributions are well described by the Wakeby distribution (WAD) with $\beta>1$ and $\gamma>0$, i.e. the WAD provides a rather more plausible description of flood sequences to better represent the long stretched upper tail structures of flood distributions, as well as the tail structures of other hydrologic phenomena (Landwehr et al., 1980). Moreover, the WAD can be considered as a parent flood distribution quite widely. It successfully used in hydrology, especially in modelling extreme events. Another study by Wilks and McKay (1996) concluded that the WAD provides the best representation of extreme snowpack water equivalent. Its application to rainfall maxima was investigated by various authors. Park et al. (2001) used the WAD with the method of L-moments estimates for summer extreme rainfall data in South Korea. Oztekin (2007) measured upper right tail estimate performances for annual extreme and partial duration precipitation series at 31 stations in the northeastern and southeastern United States, and found that L-moments of the WAD mostly gave better results than beta- $K$ and beta$P$ distributions and sometimes produced comparable results using bootstrap resampling to extrapolate the right tail behaviour. Zalina et al. (2002) and Su et al. (2009) simulated extreme precipitation over the Yangtze River Basin using the WAD, and concluded that it can adequately describe the probability distribution of precipitation extremes from both daily observational precipitation data at 147 stations in the Yangtze River Basin during 1960-2005 and projected daily data of 79 grid cells from the ECHAM5/ MPI-OM model.

In addition, Seckin et al. (2011), Soukissian (2013), Yao et al. (2013) and Rahman et al. (2015) employed the WAD for flood frequency and rainfall analyses. Busababodhin et al. (2015b) employed LH-moments to estimate WAD parameters. Simulations showed that $\mathrm{LH}$-moments estimation performed better than L-moments estimation, and they proceeded to investigate annual maximum flood and wave height data.

Here we apply the WAD and the LH-moments method introduced by Busababodhin et al. (2015b) to extreme rainfall data in Thailand, to obtain reliable quantile estimates for several return periods that we define return period in the Section Quantile Estimation. The 95\% confidence intervals for the quantiles are obtained by the bootstrap resampling technique. Isopluvial maps of the quantiles at selected return periods suitable for planners and meteorologists are presented. Section Climatology and Data in this article describes the climatology and descriptive statistics of the annual daily precipitation in Thailand. Section LH-Moments Estimation from the Wakeby Distribution presents LH-moments estimation of the WAD with our methodology and results. The quantile estimation by the bootstrap technique and isopluvial maps of the quantiles at the selected return periods are provided in Section Quantile Estimation, and Section Conclusions summarises our results.

\section{Climatology and Data}

\section{Climatology}

Thailand is tropical and the climate is also affected by the seasonal winds of the southwest and northeast monsoons. Rainfall in Thailand mainly occurs during the southwest monsoon, under the influence of the Inter-Tropical Convergence Zone (ITCZ) and tropical cyclones that produce heavy precipitation. The southwest monsoon typically starts in May, and brings a stream of warm moist air from the Indian Ocean towards Thailand producing abundant rain over the country, especially on the windward side of the mountains. The ITCZ first moves to the south during May, and then rapidly northwards to southern China around June or early July, when a dry spell occurs in northern Thailand. The ITCZ then again moves south to lie over northern and northeastern Thailand in August, and over the central and southern parts in September and October. The northeast monsoon typically starts in October, bringing cold and dry air from anticyclones over the Chinese mainland to much of Thailand, especially the north and northeast higher latitude areas but it causes milder weather and abundant rainfall along the southern-east coast, so the rainy season in southern Thailand generally differs from that in upper Thailand. During the southwest monsoon, heavy rainfall over the southern-west coast peaks in September, and at the southern-east coast in November until January. Tropical cyclones usually move across Thailand about 3 - 4 times a year, although not during January to March. 
According to historical records, from 1951 to 2011 the northeast was hit by tropical cyclones 88 times and the south 53 times, with relatively higher frequencies in September and October. The heaviest cyclone damage usually occurs in the south e.g. tropical storm "HARRIET" hit Nakhon Si Thammarat province in October 1962, typhoon "GAY" hit Chumphon province in November 1989, and the latest was the typhoon "LINDA" that hit Prachuap Khiri Khan province in November 1997. The annual rainfall for most areas of the country is 1,200 - 1,600 mm. However, some areas on the windward side including Trat province in the east and Ranong province on the southwest coast receive more than $4,000 \mathrm{~mm}$ each year. In 2014 Thailand was not directly hit by any tropical cyclone and the total average rainfall was $1520.4 \mathrm{~mm}, 4 \%$ below normal. However, there were several tropical cyclones in the area that indirectly influenced the weather e.g. typhoon "RAMMASUN", typhoon "KALMAEGI" and tropical storm "SINLAKU" that led to abundant rainfall and flash floods in late July, mid-September and late November, respectively, see Thai Meteorological (2014). In 2016, the majority of Thailand was warmer and larger rainfall than usual. The 1981-2010 normal annual rainfall averaged over the country is $1,718.1 \mathrm{~mm}$, but in 2016 it was $130.4 \mathrm{~mm}(8 \%)$ above. Moreover, rainfall of Thailand was affected by 6 tropical cyclones with 2 tropical cyclones that hit Thailand when they were depressions, namely the tropical storm "Rai" on 13 September and the tropical storm "Aere" on 14 October, 2016. Besides, rainfall in Thailand was increasing by the indirect affected of the tropical depression in the middle Vietnam in late June, the tropical storm "MIRENAE" in late July, the tropical storm "DIANMU" in the middle of August, and the tropical depression in Cambodia in early November, see Thai Meteorological (2016). The weather of Thailand in 2017 was very unusual. The average annual rainfall was 27 percent higher than normal and the highest in 67 years (1951-2017). The total rainfall throughout the month and the total rainfall throughout the year were higher than the previous statistical measurements. In addition, there were many tropical cyclones, depressions and typhoons moved into Thailand such as tropical storm "TALAS", tropical storm "SONCA" and typhoon "DOKSURI" and so on, see Thai Meteorological (2017). In 2019, Thailand had less rainfall than it used to occur. Only January and August had more rainfall than usual, as a result of the influence of tropical cyclone that moved into Thailand. It started with tropical storm "PABUK", which was the first tropical cyclone that moved to Thailand in January in 69 years. In August, there were two storms entered in Thailand, that were tropical storm "WIPHA" moved into the northern region and tropical storm "PODUL" moved into the northeast region of the country. Because in 2019 there was less rain than normal, Thailand to had a higher temperature than usual every month in many areas with the highest temperatures breaking the previous record, see Thai Meteorological (2019).

\section{Data}

In this article, we consider the time series of annual maximum precipitation constructed from monthly rainfall data during 1984 to 2019, from each of 99 stations throughout Thailand, maintained by the Thailand Meteorological Administration, see Figure 1. In Table 1, we selected stations with the two highest and lowest maximum rainfalls in each region to show sample analysis. When divided by climate characteristics, Thailand can be separated into 6 regions as follows: northern, northeastern, central, eastern, southern-east coast and southernwest coast.

The station codes, names and locations, sample sizes $(n)$, sample statistics including minimum, maximum, medians and interquartile ranges (IQR) of annual maximum precipitation (AMP), skewness and kurtosis of data computed from the time series are shown in Tables 1 and 2 , respectively. 
Table 1. Region, station code, station name, latitude and longitude for sample stations in Thailand

\begin{tabular}{|c|c|c|c|c|}
\hline Region & Code & Name & Latitude & Longitude \\
\hline \multirow{4}{*}{ Northern } & 328301 & Lampang Agromet. & 18.3166667 & 99.2833333 \\
\hline & 330201 & Phrae & 18.1666667 & 100.1666667 \\
\hline & 376401 & Umphang & 16.0247222 & 98.8644444 \\
\hline & 380201 & Kamphaeng Phet & 16.4866667 & 99.5269444 \\
\hline \multirow{4}{*}{ Northeastern } & 431201 & Nakhon Ratchasima & 14.6419444 & 101.3213889 \\
\hline & 354201 & Udon Thani & 17.3769444 & 102.8094444 \\
\hline & 357301 & Nakhon Phanom Agromet. & 17.4430556 & 104.2736111 \\
\hline & 436401 & Nang Rong & 14.5833333 & 102.8000000 \\
\hline \multirow{4}{*}{ Central } & 400301 & Tak Fah Agromet. & 15.3491667 & 100.5302778 \\
\hline & 402301 & Chai Nat Agromet. & 15.1500000 & 100.1833333 \\
\hline & 455201 & Queen Sirikit National Convention Center & 13.7263889 & 100.5600000 \\
\hline & 455601 & Don Muang & 13.9072222 & 100.5966667 \\
\hline \multirow{4}{*}{ Eastern } & 423301 & Chachoengsao Agromet. & 13.5155556 & 101.4580556 \\
\hline & 440201 & Arunya Prathet & 13.7000000 & 102.5833333 \\
\hline & 480201 & Chanthaburi & 12.6166667 & 102.1133333 \\
\hline & 501201 & Trad & 11.7802778 & 102.8780556 \\
\hline \multirow{4}{*}{ Southern-east coast } & 500301 & Nong Plub Agromet. & 12.5888889 & 99.7344444 \\
\hline & 552301 & Nakhon Si Thammarat Agromet. & 8.3591667 & 100.0594444 \\
\hline & 568501 & Songkhla & 7.1822222 & 100.6075000 \\
\hline & 568502 & Hat Yai & 6.9180556 & 100.4333333 \\
\hline \multirow{4}{*}{ Southern-west coast } & 532201 & Ranong & 9.9833333 & 98.6166667 \\
\hline & 564201 & Phuket & 7.8833333 & 98.4000000 \\
\hline & 566201 & Lun Ta (Krabi) & 7.5333333 & 99.0500000 \\
\hline & 570201 & Satun & 6.6500000 & 100.0833333 \\
\hline
\end{tabular}




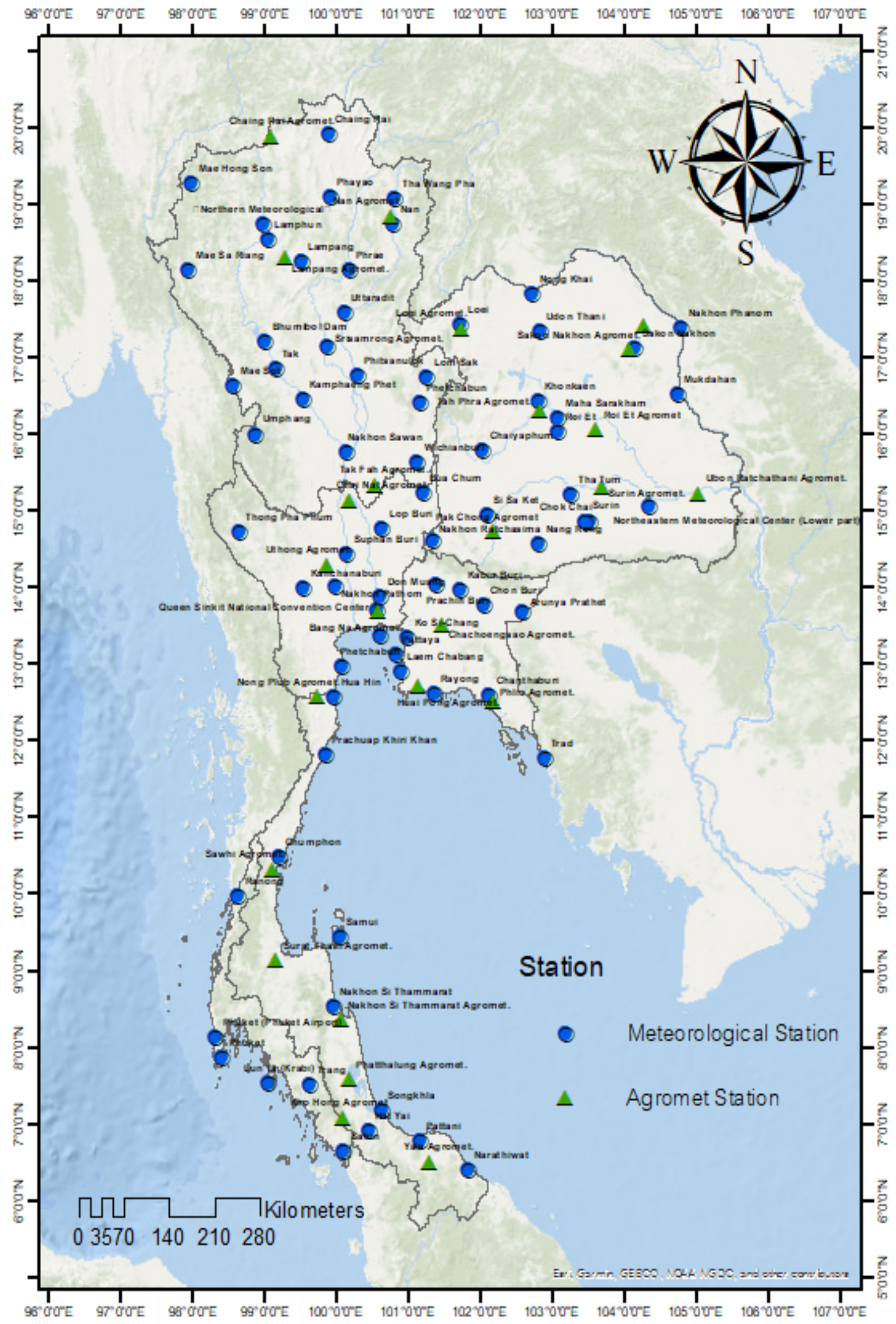

Figure 1. The location of weather stations in Thailand 
Table 2. Station code, sizes, minimum, maximum, median, interquartile range (IQR) of AMP, skewness and kurtosis for sample stations in Thailand from monthly rainfall data during 1984 to 2019

\begin{tabular}{|c|c|c|c|c|c|c|c|}
\hline Code & $\begin{array}{c}\text { Size } \\
(n)\end{array}$ & $\begin{array}{c}\text { Minimum } \\
\text { (unit; } \mathrm{mm} \text { ) }\end{array}$ & $\begin{array}{l}\text { Maximum } \\
\text { (unit; } \mathrm{mm} \text { ) }\end{array}$ & $\begin{array}{c}\text { Median } \\
\text { (unit; } \mathrm{mm} \text { ) }\end{array}$ & $\begin{array}{c}\text { IQR } \\
\text { (unit; } \mathbf{m m} \text { ) }\end{array}$ & Skewness & Kurtosis \\
\hline 328301 & 36 & 6.70 & $114.40^{*}$ & 20.73 & 70.25 & -0.33 & 4.95 \\
\hline 330201 & 36 & 43.30 & 218.20 & 22.75 & 80.10 & 2.07 & 8.15 \\
\hline 376401 & 36 & 33.90 & 124.70 & 16.53 & 70.85 & 0.61 & 3.99 \\
\hline 380201 & 36 & 49.20 & $248.90^{*}$ & 18.70 & 83.25 & 2.69 & 11.68 \\
\hline 431201 & 36 & 50.10 & $129.70^{* *}$ & 32.60 & 76.40 & 0.55 & 2.17 \\
\hline 354201 & 36 & 54.20 & $274.50^{*}$ & 31.50 & 90.90 & 2.37 & 9.88 \\
\hline 357301 & 36 & 71.50 & 272.60 & 53.00 & 124.00 & 1.18 & 3.96 \\
\hline 436401 & 36 & 45.70 & 130.50 & 31.53 & 90.25 & 0.03 & 2.30 \\
\hline 400301 & 36 & 52.90 & 116.70 & 28.23 & 81.35 & 0.14 & 1.92 \\
\hline 402301 & 36 & 41.00 & $107.80^{* *}$ & 21.55 & 69.90 & 0.35 & 2.53 \\
\hline 455201 & 36 & 40.20 & $216.80^{*}$ & 52.58 & 93.95 & 0.82 & 3.19 \\
\hline 455601 & 36 & 58.40 & 210.70 & 33.68 & 98.60 & 1.71 & 6.56 \\
\hline 423301 & 36 & 49.00 & 144.60 & 32.33 & 79.05 & 0.95 & 3.22 \\
\hline 440201 & 36 & 45.70 & $142.80^{* *}$ & 17.88 & 74.80 & 1.18 & 5.09 \\
\hline 480201 & 36 & 84.70 & 394.90 & 59.48 & 138.75 & 2.22 & 9.32 \\
\hline 501201 & 36 & 127.50 & $445.30^{*}$ & 139.58 & 225.00 & 0.58 & 2.20 \\
\hline 500301 & 36 & 45.20 & 226.00 & 37.73 & 83.60 & 1.36 & 4.20 \\
\hline 552301 & 36 & 64.90 & $615.60^{*}$ & 104.60 & 146.60 & 2.08 & 8.15 \\
\hline 568501 & 36 & 71.20 & 521.80 & 115.85 & 155.35 & 1.46 & 5.09 \\
\hline 568502 & 36 & 51.00 & $219.40^{* *}$ & 31.75 & 100.80 & 1.21 & 4.14 \\
\hline 532201 & 36 & 116.50 & $249.70^{*}$ & 37.03 & 162.70 & 0.48 & 3.10 \\
\hline 564201 & 36 & 70.00 & $180.70^{* *}$ & 45.85 & 102.45 & 0.75 & 2.44 \\
\hline 566201 & 36 & 73.00 & 241.60 & 41.25 & 122.10 & 1.33 & 4.55 \\
\hline 570201 & 36 & 67.00 & 207.80 & 43.90 & 108.05 & 0.94 & 3.58 \\
\hline
\end{tabular}




\section{Results and discussion}

\section{LH-Moments Estimation from the Wakeby Distribution}

LH-moments are expected to characterise the upper part of distributions well, as they generally emphasise high upper distribution quantiles rather than lower quantiles (Wang, 1997). LH-moments estimation procedure is more reliable than the classical method of moments estimation, particularly for small sample sizes, and is usually computationally more tractable than maximum likelihood estimation. The definition of LH-moment with order $\eta=0,1,2, \ldots$ for $r=1,2, \ldots$ as defined by Wang(1997) are

$$
\lambda_{r}^{\eta}=\sum_{k=0}^{r-1} C_{r, k} E\left[X_{\eta+r-k: \eta+r}\right]
$$

where $C_{r, k}=(-1)^{k}\left(\begin{array}{c}r-1 \\ k\end{array}\right)$.

Furthermore, Park et al (2001) showed the use of linear combination moments instead of conventional product moments and the resistance to the presence of any outliers present in the sample, due to the occurrence of heavy rainfall and typhoon events, means the method is quite robust.

The Wakeby distribution quantile function has the form

$$
x(F)=\xi+\frac{\alpha}{\beta}\left[1-(1-F)^{\beta}\right]-\frac{\gamma}{\delta}\left[1-(1-F)^{-\delta}\right]
$$

where $F \equiv F(x)=P[X \leq x], \xi$ is the location parameter and $\alpha, \beta, \gamma$ and $\delta$ are other parameters. The parameter $\alpha$ largely relates to the scale of the variable while $\beta, \gamma$ and $\delta$ are exponential parameters defining the shape of the quantile function. The parameterisation explicitly exhibits the WAD as a generalisation of the generalised Pareto distribution for which $\alpha=0$ or $\gamma=0$ and provides estimates of the $\alpha$ and $\gamma$ parameters that are more stable under small perturbations of the data.

The population LH-moments of the WAD, see Busababodhin et al. (2015b):

$$
\begin{aligned}
& \lambda_{1}^{\eta}=\xi+\frac{\alpha}{\beta}\left[1-(\eta+1) T_{1}\right]-\frac{\gamma}{\delta}\left[1-(\eta+1) D_{1}\right], \\
& \lambda_{2}^{\eta}=\frac{\eta+2}{2}\left[\begin{array}{l}
\frac{\alpha}{\beta}\left((\eta+1) T_{1}-(\eta+2) T_{2}\right) \\
\left.-\frac{\gamma}{\delta}\left((\eta+1) D_{1}-(\eta+2) D_{2}\right)\right]
\end{array}\right], \\
& \lambda_{3}^{\eta}=\frac{\eta+3}{3 !}\left[\begin{array}{l}
\frac{\alpha}{\beta}\left(-W_{3} T_{3}+2 W_{2} T_{2}-W_{1} T_{1}\right) \\
-\frac{\gamma}{\delta}\left(-W_{3} D_{3}+2 W_{2} D_{2}-W_{1} D_{1}\right)
\end{array}\right], \\
& \lambda_{4}^{\eta}=\frac{\eta+4}{4 !}\left[\begin{array}{l}
\frac{\alpha}{\beta}\left(-G_{4} T_{4}+3 G_{3} T_{3}-3 G_{2} T_{2}+G_{1} T_{1}\right) \\
-\frac{\gamma}{\delta}\left(-G_{4} D_{4}+3 G_{3} D_{3}-3 G_{2} D_{2}+G_{1} D_{1}\right)
\end{array}\right], \\
& \lambda_{5}^{\eta}=\frac{\eta+5}{5 !}\left[\begin{array}{l}
\frac{\alpha}{\beta}\left(-Y_{5} T_{5}+4 Y_{4} T_{4}-6 Y_{3} T_{3}+4 Y_{2} T_{2}-Y_{1} T_{1}\right) \\
-\frac{\gamma}{\delta}\left(-Y_{5} D_{5}+4 Y_{4} D_{4}-6 Y_{3} D_{3}+4 Y_{2} D_{2}-Y_{1} D_{1}\right)
\end{array}\right] .
\end{aligned}
$$

where $T_{l}=\mathrm{B}(\eta+l, \beta+1)$ and $D_{l}=\mathrm{B}(\eta+l, 1-\delta)$ for $\mathrm{B}$ been the beta function, $\eta=0,1,2,3,4$, $l=1,2,3,4,5$, and

$W_{i}=(\eta+i+1)(\eta+i)$ for $i=1,2,3$,

$G_{j}=(\eta+j+2)(\eta+j+1)(\eta+j+1)(\eta+j)$ for $j=1,2,3,4$,

$Y_{k}=(\eta+k+3)(\eta+k+2)(\eta+k+1)(\eta+k)$ for $k=1,2,3,4,5$. 
When $\eta=0$, the LH-moments reduce to L-moments. Here we consider the following constraints for the existence of LH-moments for the WAD, which are the same as the constraints for the WAD function. It is assumed that $\beta+\delta \geq 0$; and the range of $x$ is $\xi \leq x \leq \infty$ if $\delta \geq 0$ and $\gamma \geq 0$, or $\xi \leq x \leq \xi+\frac{\alpha}{\beta}-\frac{\gamma}{\delta}$ if $\delta<0$ or $\gamma=0$. For $x(F)$ to be a valid quantile function, the conditionals $\gamma \geq 0$ and $\alpha+\gamma \geq 0$ must also hold (Hosking, 1986).

The sample LH-moments are obtained from the given observational data, see Busababodhin et al. (2015b). No explicit solution of the simultaneous equations is possible in the WAD, but the equations may be solved by an augmented Lagrangian adaptive barrier minimisation algorithm for optimising smooth nonlinear objective functions with nonlinear constraints. Varadhan (2012) introduced a nonlinear optimisation algorithm in the statistical software R for nonlinear constraints, involving the optimisation function "auglag" in the R package "alabama". The elaborated form is an augmented lagrangian adaptive barrier minimisation algorithm for optimising smooth nonlinear objective functions with nonlinear constraints.

The order $(\eta)$, parameter estimates (LH-moments) of the WAD, and the Kolmogorov-Smirnov's goodness-of-fit statistic $D(\mathrm{KS}-D)$ at each station are given in Table 3 . The p-values here are computed by the formula from Press et al. (1996, p.618), as if the parameters of the WAD are specified. If the estimated $p$-value is less than 0.1 , then a more accurate way in the simulation is to compute the true $p$ value, see Ross (1990, section 9.2). It can be seen from Table 3 that, there are 2 stations with $p$-values less than 0.1 which are 0.054 and 0.052 at sites 455601 and 552301 , respectively. There are only 3 stations (or $12.5 \%$ ) with $\eta=0$ and 21 stations (or $87.5 \%$ ) with other values of $\eta$. Therefore, there is a strong evidence that the WAD modelling with LH-moments method approach is more accurate for each of the stations than the L-moments method. Figure 2 shows the order $\eta$ of the WAD for weather stations in Thailand and Figure 3 shows the relative frequency histogram with various $\eta$ values corresponding to LH-moments for the WAD at station 455201.

From Figure 3, solid black line is for eta $=0$, red dashed for eta $=1$, green dashed for eta $=2$, blue dashed for eta $=3$, and gray dashed for eta $=4$. The result shows relative frequency histogram at station 455201 when using LH-moments $(\eta=0,1,2,3$ and 4$)$ for the WAD. We can see that $\eta=0$ and 1 are almost fit to the relative frequency histogram of real data set. However, the $\eta=1$ is the best fit to the real data set that imply LH-moments method is better than L-moments method.

\section{Quantile Estimation}

The quantile or the design value corresponding to a return period of $T$ years ( $T$ years return value) is defined by the magnitude $x(F)$ with $F=1-1 / T$. The design values were computed via Eq. (2), and the confidence interval of the return value $q(T)$ was obtained by the bootstrap resampling technique. The design values and $95 \%$ confidence intervals corresponding to 2, 5, 10, 25 and 50 years computed from the annual extreme rainfall at each station are presented in Table 4. We use the Percentile Bootstrap confidence interval with the number of replications 2000. For more discussion on bootstrap confidence intervals for predicted rainfall quantiles, see Dunn (2001). Isopluvial (rainfall frequency) maps of the estimated design values corresponding to selected return periods of 2, 5, 10, 25 and 50 years for the AMP using the values from the 99 stations are presented in Figures 4 to 8, respectively.

The highest return values were for the sites in the windward side of the eastern and southern-east coast parts of Thailand, due to the influence of typhoons or tropical storms. Thailand is subject to tropical depressions further inland, although some mountain ranges obstruct the wind, and in the southern-east coast there is also a relatively high risk of typhoons and tropical storms. In Table 4, it shows that, the site 501201 at Trad shows the highest return values of 2, 5, 10, and 25 years and the site 552301 at Nakhon Si Thammarat Agrome shows the highest return value of 50 year, with a large range of confidence intervals compared to the real data in Table 4. Moreover, both of these stations also show the top two highest rainfall. In general, the quantile estimation from our estimation and distribution approach is similar to the real rainfall data. 
Table 3. Station code, order, parameter estimates ( $\mathrm{LH}$-moments) of the WAD, and KS-D's statistic computed from the 24 stations in Thailand.

\begin{tabular}{|c|c|c|c|c|c|c|c|c|}
\hline \multirow{2}{*}{ Code } & \multirow{2}{*}{$\begin{array}{c}\text { Order } \\
(\eta)\end{array}$} & \multicolumn{5}{|c|}{ parameter estimate } & \multirow{2}{*}{ KS-D } & \multirow{2}{*}{ p-value } \\
\hline & & $\xi$ & $\alpha$ & $\beta$ & $\gamma$ & $\delta$ & & \\
\hline 328301 & 2 & 45.087 & 40.841 & 3.019 & 13.364 & 0.011 & 0.126 & 0.617 \\
\hline 330201 & 1 & 55.475 & 23.567 & 2.756 & 17.439 & 0.287 & 0.139 & 0.491 \\
\hline 376401 & 1 & 42.860 & 65.516 & 3.639 & 11.052 & 0.121 & 0.150 & 0.392 \\
\hline 380201 & 1 & 67.557 & 1.485 & 7.350 & 15.748 & 0.361 & 0.169 & 0.256 \\
\hline 431201 & 2 & 60.356 & -70.340 & 2.828 & 77.086 & -0.751 & 0.139 & 0.491 \\
\hline 354201 & 1 & 63.683 & 29.527 & 3.442 & 20.536 & 0.312 & 0.130 & 0.581 \\
\hline 357301 & 2 & 83.181 & 1.088 & 15.983 & 58.388 & -0.103 & 0.083 & 0.948 \\
\hline 436401 & 1 & 60.640 & 5.796 & 11.305 & 53.303 & -0.678 & 0.083 & 0.946 \\
\hline 400301 & 0 & 52.885 & -0.540 & 16.007 & 52.660 & -0.885 & 0.078 & 0.980 \\
\hline 402301 & 1 & 51.823 & 1.121 & 15.983 & 31.926 & -0.449 & 0.095 & 0.903 \\
\hline 455201 & 1 & 53.919 & 3.830 & 6.033 & 61.668 & -0.241 & 0.076 & 0.985 \\
\hline 455601 & 2 & 58.731 & 46.391 & 1.484 & 9.279 & 0.424 & 0.224 & 0.054 \\
\hline 423301 & 0 & 52.422 & 117.628 & 18.364 & 30.301 & -0.181 & 0.115 & 0.723 \\
\hline 440201 & 1 & 50.598 & 49.984 & 3.166 & 11.127 & 0.196 & 0.181 & 0.188 \\
\hline 480201 & 1 & 83.112 & 64.622 & 2.149 & 27.879 & 0.299 & 0.163 & 0.262 \\
\hline 501201 & 3 & 98.637 & 1.056 & 15.981 & 236.555 & -0.622 & 0.166 & 0.244 \\
\hline 500301 & 1 & 50.432 & 7.767 & 14.230 & 46.070 & -0.002 & 0.087 & 0.926 \\
\hline 552301 & 0 & 54.940 & 83.433 & 2.397 & 68.550 & 0.209 & 0.225 & 0.052 \\
\hline 568501 & 2 & 80.932 & 4.608 & 4.782 & 100.016 & 0.018 & 0.111 & 0.724 \\
\hline 568502 & 3 & 62.592 & 1.021 & 15.996 & 46.588 & -0.054 & 0.149 & 0.364 \\
\hline 532201 & 1 & 131.508 & 3.505 & 6.241 & 46.952 & -0.324 & 0.139 & 0.491 \\
\hline 564201 & 3 & 77.520 & 1.233 & 7.386 & 45.015 & -0.182 & 0.066 & 0.997 \\
\hline 566201 & 1 & 81.869 & 42.181 & 4.407 & 34.990 & 0.034 & 0.070 & 0.995 \\
\hline 570201 & 2 & 81.172 & 1.565 & 7.245 & 38.234 & -0.101 & 0.125 & 0.625 \\
\hline
\end{tabular}




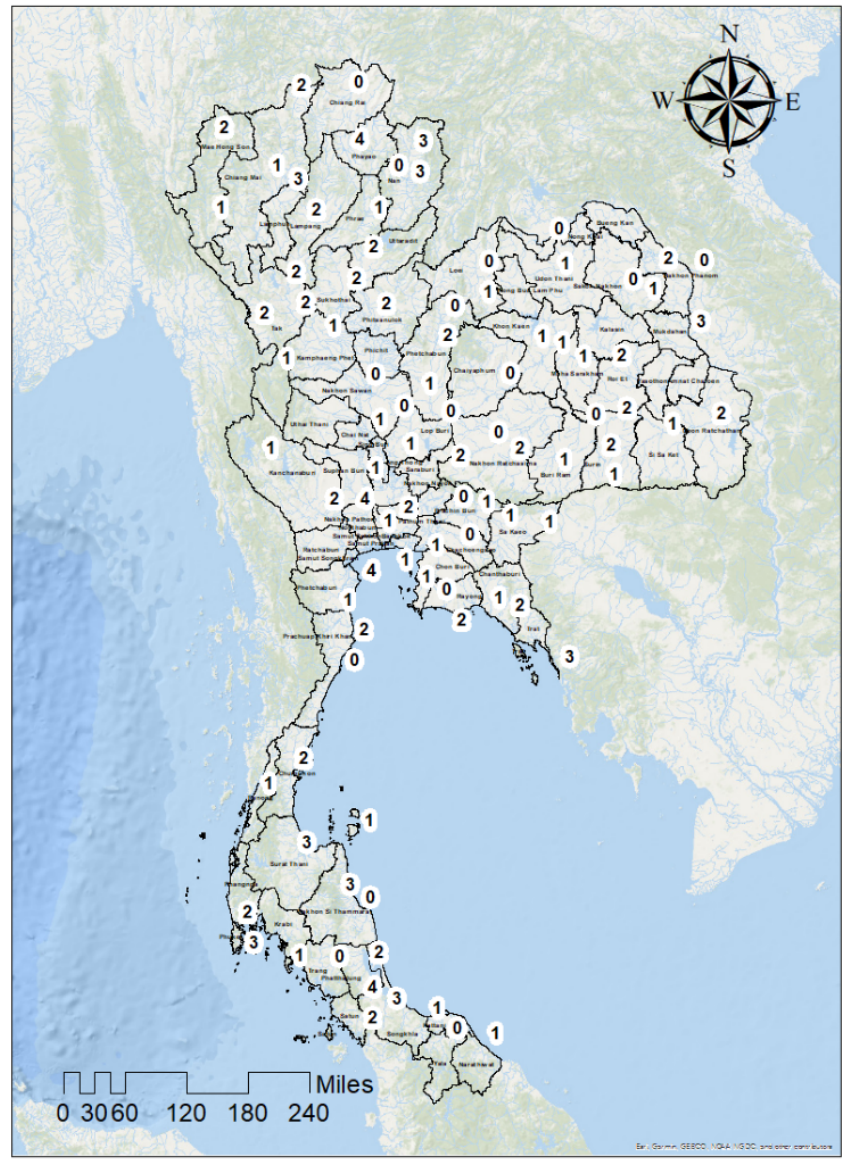

Figure 2. The order, $\eta$, of the WAD for weather stations in Thailand.

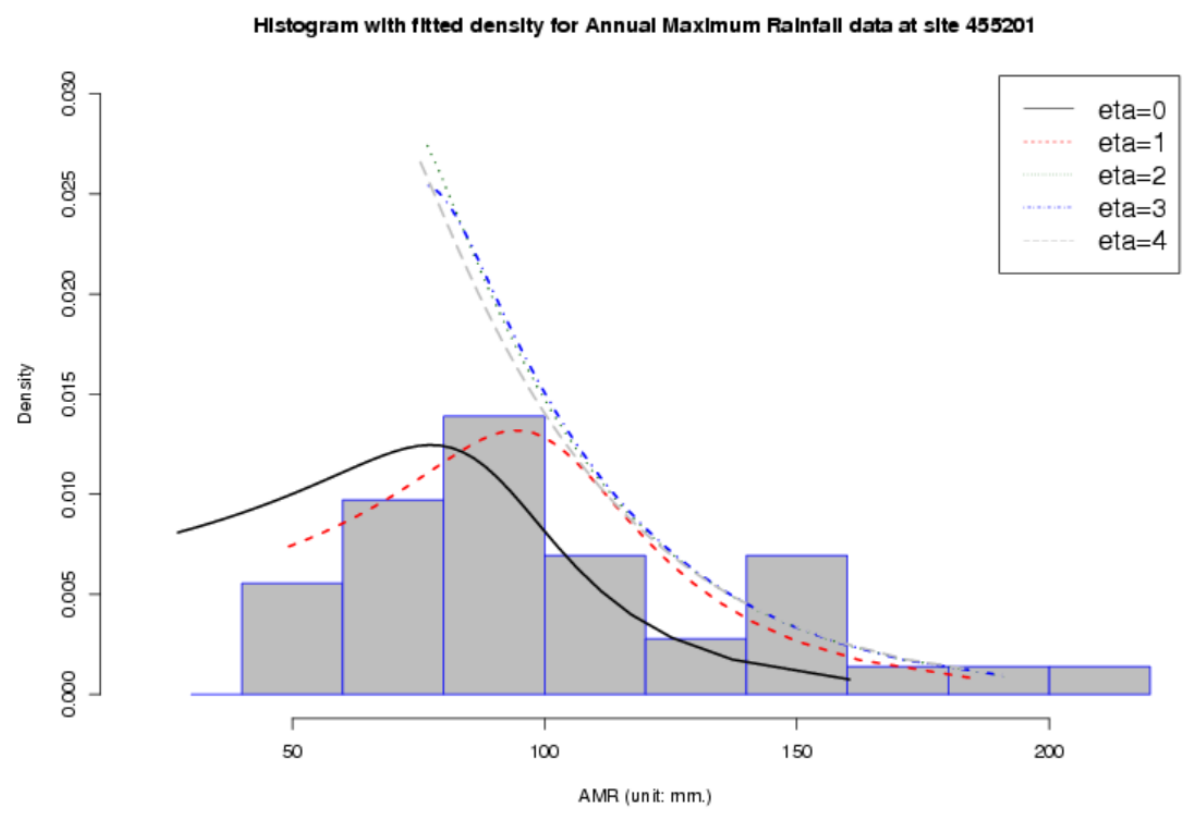

Figure 3. Relative frequency histogram and probability functions fitted for AMP data at station 455201 when using LH-moments for the WAD. 
Table 4. Station code, return level (unit, $\mathrm{mm}$ ) corresponding to various return periods ( $T$ ) computed from the time series of annual extreme rainfall for 24 stations in Thailand.

\begin{tabular}{|c|c|c|c|c|c|c|}
\hline \multirow{2}{*}{ Code } & \multirow{2}{*}{$\begin{array}{l}\text { Order } \\
(\eta)\end{array}$} & \multicolumn{5}{|c|}{ Return level (unit; mm) } \\
\hline & & $T=2$ & $T=5$ & $T=10$ & $T=25$ & $T=50$ \\
\hline 328301 & 2 & $\begin{array}{c}66.25 \\
(13.25,72.34) \\
\end{array}$ & $\begin{array}{c}80.21 \\
(30.27,92.13) \\
\end{array}$ & $\begin{array}{c}89.77 \\
(38.19,103.97)\end{array}$ & $\begin{array}{c}102.42 \\
(46.77,115.80)\end{array}$ & $\begin{array}{c}112.06 \\
(51.16,122.75)\end{array}$ \\
\hline 330201 & 1 & $\begin{array}{c}76.13 \\
(14.64,84.53) \\
\end{array}$ & $\begin{array}{c}99.60 \\
(38.66,118.82) \\
\end{array}$ & $\begin{array}{c}120.92 \\
(51.13,145.06)\end{array}$ & $\begin{array}{c}156.35 \\
(64.26,188.52)\end{array}$ & $\begin{array}{c}190.05 \\
(71.18,226.76)\end{array}$ \\
\hline 376401 & 1 & $\begin{array}{c}67.41 \\
(12.62,72.55) \\
\end{array}$ & $\begin{array}{c}80.45 \\
(32.31,88.11) \\
\end{array}$ & $\begin{array}{c}90.21 \\
(43.47,99.19) \\
\end{array}$ & $\begin{array}{c}104.38 \\
(53.80,115.07)\end{array}$ & $\begin{array}{c}116.18 \\
(58.05,127.48)\end{array}$ \\
\hline 380201 & 1 & $\begin{array}{c}80.16 \\
(14.06,107.33) \\
\end{array}$ & $\begin{array}{c}102.12 \\
(38.41,129.48) \\
\end{array}$ & $\begin{array}{c}124.30 \\
(51.45,156.10) \\
\end{array}$ & $\begin{array}{c}163.56 \\
(65.23,204.14) \\
\end{array}$ & $\begin{array}{c}203.20 \\
(72.10,255.07) \\
\end{array}$ \\
\hline 431201 & 2 & $\begin{array}{c}80.65 \\
(20.02,83.78) \\
\end{array}$ & $\begin{array}{c}107.76 \\
(43.33,110.44) \\
\end{array}$ & $\begin{array}{c}119.98 \\
(55.87,122.67) \\
\end{array}$ & $\begin{array}{c}129.02 \\
(66.07,132.47) \\
\end{array}$ & $\begin{array}{c}132.73 \\
(72.53,136.98) \\
\end{array}$ \\
\hline 354201 & 1 & $\begin{array}{c}87.36 \\
(10.55,96.71) \\
\end{array}$ & $\begin{array}{c}115.16 \\
(37.59,136.67) \\
\end{array}$ & $\begin{array}{c}141.45 \\
(54.50,170.15) \\
\end{array}$ & $\begin{array}{c}186.13 \\
(71.38,224.56) \\
\end{array}$ & $\begin{array}{c}229.51 \\
(80.68,271.58) \\
\end{array}$ \\
\hline 357301 & 2 & $\begin{array}{c}122.32 \\
(4.47,133.91) \\
\end{array}$ & $\begin{array}{c}169.88 \\
(51.09,197.81) \\
\end{array}$ & $\begin{array}{c}203.00 \\
(72.38,234.36) \\
\end{array}$ & $\begin{array}{c}243.32 \\
(91.94,271.71) \\
\end{array}$ & $\begin{array}{c}271.40 \\
(103.19,294.51) \\
\end{array}$ \\
\hline 436401 & 1 & $\begin{array}{c}90.63 \\
(30.52,96.69) \\
\end{array}$ & $\begin{array}{c}113.36 \\
(52.01,119.30) \\
\end{array}$ & $\begin{array}{c}123.25 \\
(64.36,127.59) \\
\end{array}$ & $\begin{array}{c}130.88 \\
(75.78,132.70) \\
\end{array}$ & $\begin{array}{c}134.20 \\
(82.40,135.86) \\
\end{array}$ \\
\hline 400301 & 0 & $\begin{array}{c}80.14 \\
(23.01,87.81) \\
\end{array}$ & $\begin{array}{c}98.04 \\
(41.59,104.35) \\
\end{array}$ & $\begin{array}{c}104.61 \\
(47.91,108.53) \\
\end{array}$ & $\begin{array}{c}108.92 \\
(52.76,112.05) \\
\end{array}$ & $\begin{array}{c}110.50 \\
(54.48,114.68) \\
\end{array}$ \\
\hline 402301 & 1 & $\begin{array}{c}70.91 \\
(13.53,82.56) \\
\end{array}$ & $\begin{array}{c}88.49 \\
(29.89,101.14) \\
\end{array}$ & $\begin{array}{c}97.73 \\
(39.33,111.64) \\
\end{array}$ & $\begin{array}{c}106.27 \\
(50.27,121.03) \\
\end{array}$ & $\begin{array}{c}110.76 \\
(57.00,125.19) \\
\end{array}$ \\
\hline 455201 & 1 & $\begin{array}{c}93.91 \\
(3.28,105.17) \\
\end{array}$ & $\begin{array}{c}136.83 \\
(42.97,151.73) \\
\end{array}$ & $\begin{array}{c}163.54 \\
(60.91,178.22) \\
\end{array}$ & $\begin{array}{c}192.66 \\
(74.61,209.32) \\
\end{array}$ & $\begin{array}{c}210.78 \\
(80.73,229.84) \\
\end{array}$ \\
\hline 455601 & 2 & $\begin{array}{c}86.29 \\
(8.57,99.17) \\
\end{array}$ & $\begin{array}{c}108.53 \\
(32.85,123.50)\end{array}$ & $\begin{array}{c}125.16 \\
(45.32,146.41)\end{array}$ & $\begin{array}{c}153.48 \\
(57.52,181.60)\end{array}$ & $\begin{array}{c}182.89 \\
(66.24,213.66)\end{array}$ \\
\hline 423301 & 0 & $\begin{array}{c}78.56 \\
(2.04,83.37) \\
\end{array}$ & $\begin{array}{c}101.12 \\
(24.61,108.23)\end{array}$ & $\begin{array}{c}115.86 \\
(37.57,123.56)\end{array}$ & $\begin{array}{c}132.70 \\
(50.76,141.36)\end{array}$ & $\begin{array}{c}143.71 \\
(58.32154 .76)\end{array}$ \\
\hline 440201 & 1 & $\begin{array}{c}72.89 \\
(15.70,79.60) \\
\end{array}$ & $\begin{array}{c}87.35 \\
(36.05,100.02) \\
\end{array}$ & $\begin{array}{c}98.76 \\
(46.98,115.97) \\
\end{array}$ & $\begin{array}{c}116.32 \\
(56.80,136.24) \\
\end{array}$ & $\begin{array}{c}131.86 \\
(62.05,151.88) \\
\end{array}$ \\
\hline 480201 & 1 & $\begin{array}{c}127.88 \\
(7.48,140.73) \\
\end{array}$ & $\begin{array}{c}169.89 \\
(51.84,193.48) \\
\end{array}$ & $\begin{array}{c}205.39 \\
(75.84,238.32) \\
\end{array}$ & $\begin{array}{c}264.13 \\
(100.10,305.39) \\
\end{array}$ & $\begin{array}{c}320.44 \\
(112.68,375.12) \\
\end{array}$ \\
\hline 501201 & 3 & $\begin{array}{c}231.90 \\
(26.79,248.30) \\
\end{array}$ & $\begin{array}{c}339.25 \\
(121.51,356.28) \\
\end{array}$ & $\begin{array}{c}388.19 \\
(171.37,399.65) \\
\end{array}$ & $\begin{array}{c}427.64 \\
(215.88,432.81) \\
\end{array}$ & $\begin{array}{c}445.62 \\
(236.95,446.37) \\
\end{array}$ \\
\hline 500301 & 1 & $\begin{array}{c}82.88 \\
(7.25,96.68)\end{array}$ & $\begin{array}{c}124.98 \\
(42.78,154.32)\end{array}$ & $\begin{array}{c}156.76 \\
(55.11,186.60) \\
\end{array}$ & $\begin{array}{c}198.69 \\
(66.83,225.28) \\
\end{array}$ & $\begin{array}{c}230.35 \\
(75.55,253.84) \\
\end{array}$ \\
\hline 552301 & 0 & $\begin{array}{c}134.26 \\
(8.55,169.12) \\
\end{array}$ & $\begin{array}{c}220.13 \\
(80.81,280.89) \\
\end{array}$ & $\begin{array}{c}292.26 \\
(114.23,368.94) \\
\end{array}$ & $\begin{array}{c}404.31 \\
(142.29,501.47) \\
\end{array}$ & $\begin{array}{c}504.40 \\
(154.72,624.23) \\
\end{array}$ \\
\hline 568501 & 2 & $\begin{array}{c}151.62 \\
(8.98,173.14)\end{array}$ & $\begin{array}{c}245.22 \\
(80.60,297.34)\end{array}$ & $\begin{array}{c}317.04 \\
(113.13,371.88) \\
\end{array}$ & $\begin{array}{c}413.37 \\
(139.11,468.84) \\
\end{array}$ & $\begin{array}{c}487.30 \\
(154.08,536.93)\end{array}$ \\
\hline 568502 & 3 & $\begin{array}{c}94.35 \\
(3.27,103.99) \\
\end{array}$ & $\begin{array}{c}134.47 \\
(48.64,154.10) \\
\end{array}$ & $\begin{array}{c}163.53 \\
(62.57,188.15) \\
\end{array}$ & $\begin{array}{c}200.30 \\
(77.45,220.43) \\
\end{array}$ & $\begin{array}{c}226.94 \\
(85.78,239.23) \\
\end{array}$ \\
\hline 532201 & 1 & $\begin{array}{c}161.21 \\
(30.40,163.24)\end{array}$ & $\begin{array}{c}190.97 \\
(63.83,187.72)\end{array}$ & $\begin{array}{c}208.28 \\
(85.03,203.32)\end{array}$ & $\begin{array}{c}225.94 \\
(106.66,224.25) \\
\end{array}$ & $\begin{array}{c}236.23 \\
(120.21,240.90)\end{array}$ \\
\hline 564201 & 3 & $\begin{array}{c}107.00 \\
(4.87,110.65) \\
\end{array}$ & $\begin{array}{c}140.48 \\
(40.63,147.66) \\
\end{array}$ & $\begin{array}{c}162.34 \\
(58.42,170.75) \\
\end{array}$ & $\begin{array}{c}187.31 \\
(74.99,195.61) \\
\end{array}$ & $\begin{array}{c}203.61 \\
(83.26,213.38) \\
\end{array}$ \\
\hline 566201 & 1 & $\begin{array}{c}113.14 \\
(9.67,124.17) \\
\end{array}$ & $\begin{array}{c}147.89 \\
(44.88,168.79)\end{array}$ & $\begin{array}{c}174.21 \\
(61.83,199.82) \\
\end{array}$ & $\begin{array}{c}211.13 \\
(76.42,236.99)\end{array}$ & $\begin{array}{c}240.97 \\
(86.07,261.96)\end{array}$ \\
\hline 570201 & 2 & $\begin{array}{c}106.98 \\
(7.12,113.85) \\
\end{array}$ & $\begin{array}{c}138.19 \\
(40.89,147.24) \\
\end{array}$ & $\begin{array}{c}159.96 \\
(56.44,169.95) \\
\end{array}$ & $\begin{array}{c}186.50 \\
(70.46,194.99) \\
\end{array}$ & $\begin{array}{c}205.00 \\
(78.21,212.38) \\
\end{array}$ \\
\hline
\end{tabular}




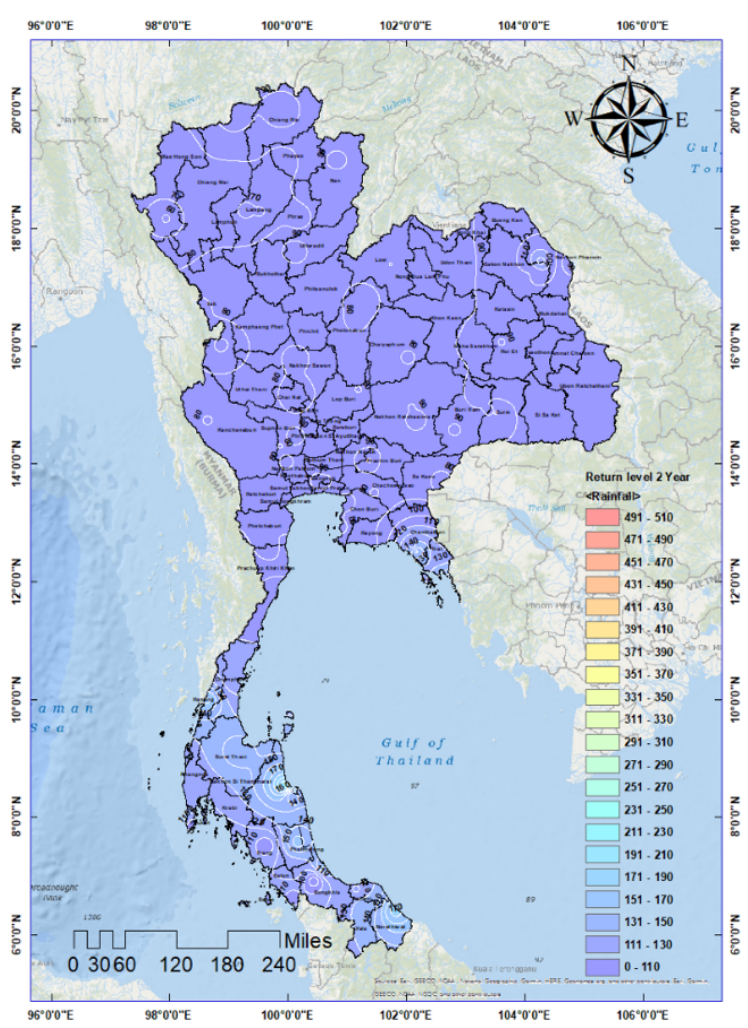

Figure 4. Isopluvial map of the estimated design value (unit; $\mathrm{mm}$ ) corresponding to 2-year return period

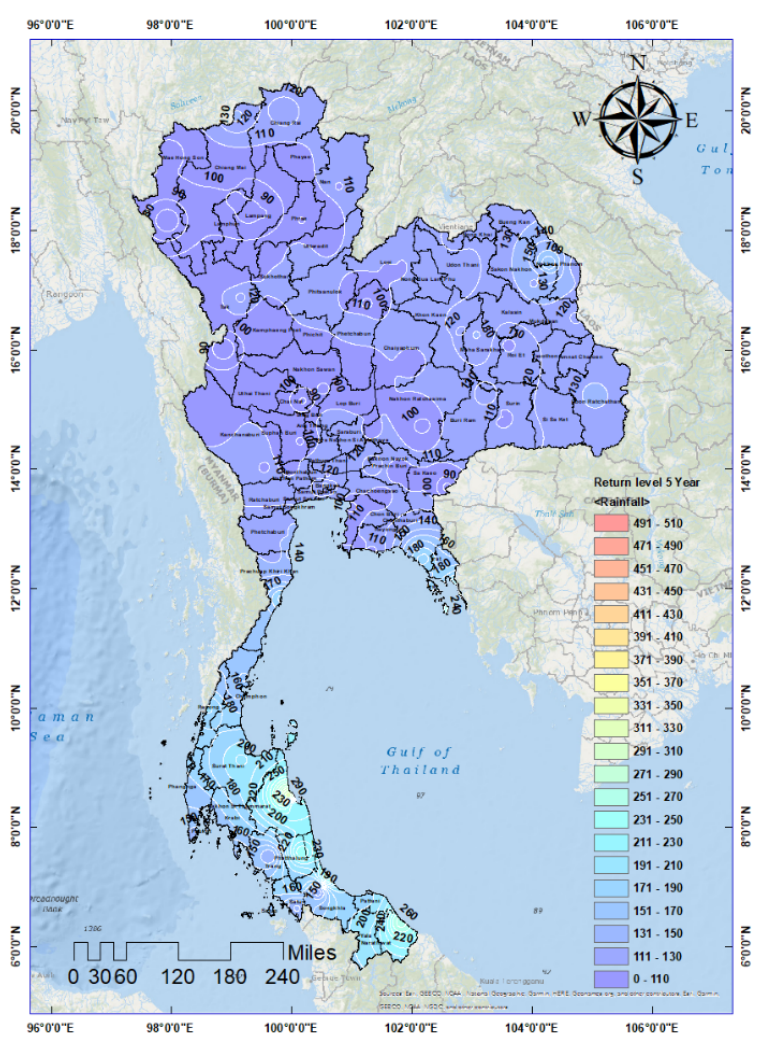

Figure 5. Isopluvial map of the estimated design value (unit; $\mathrm{mm}$ ) corresponding to 5-year return period 


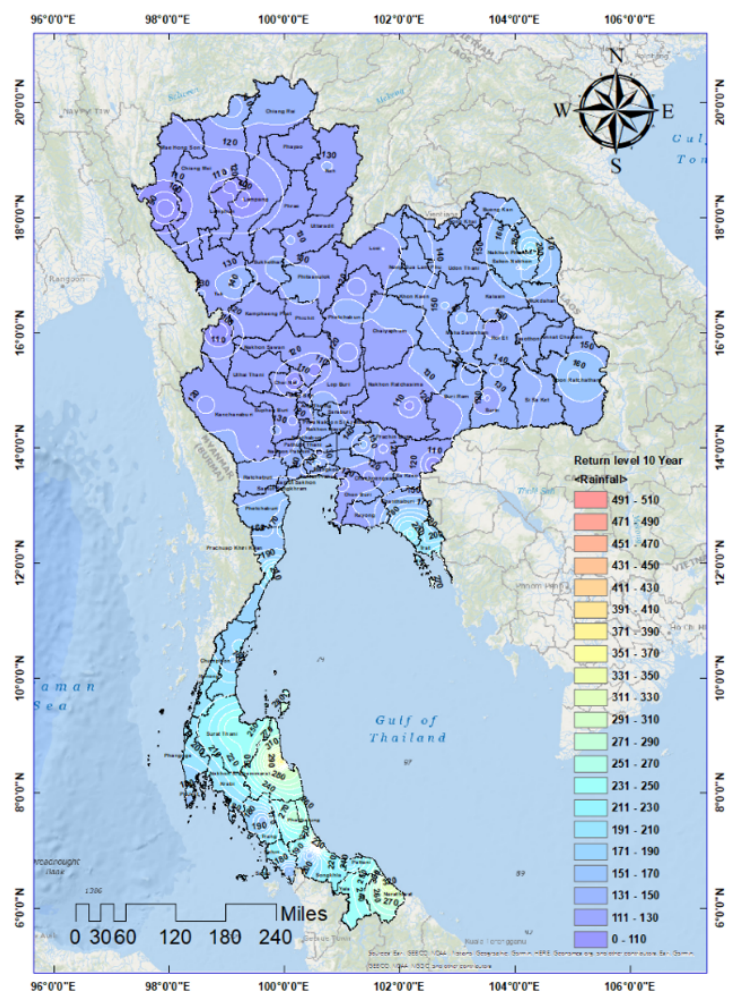

Figure 6. Isopluvial map of the estimated design value (unit; $\mathrm{mm}$ ) corresponding to 10 -year return period

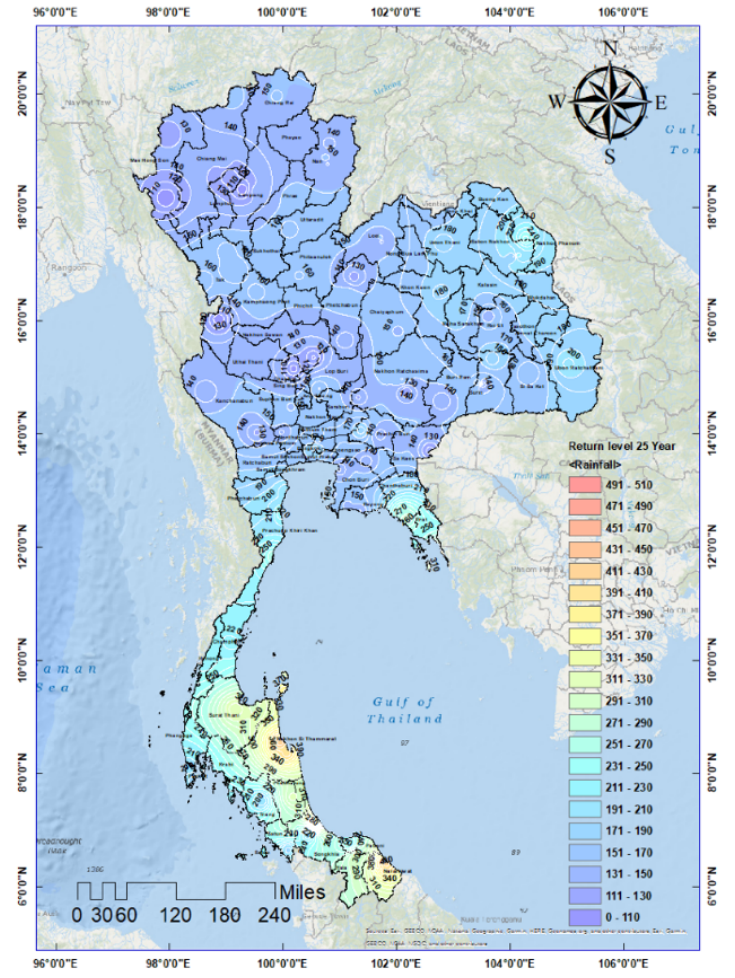

Figure 7. Isopluvial map of the estimated design value (unit; $\mathrm{mm}$ ) corresponding to 25 year return period. 


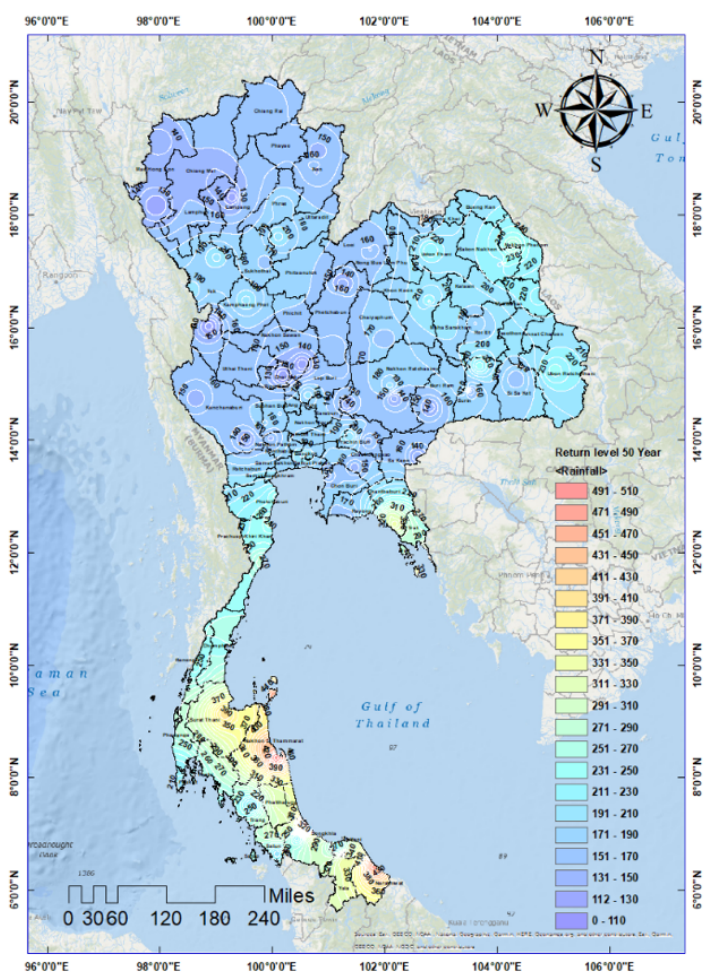

Figure 8. Isopluvial map of the estimated design value (unit; $\mathrm{mm}$ ) corresponding to 50-year return period.

\section{Conclusions}

Extreme rainfall has posed a significant challenge for statistical modelling. Recent research on the GEVD using several methods of estimation (L-moment, MLE, and probability weighted moments) to model extreme rainfall involved three distribution parameters. Park et al. (2001) used the WAD instead of the K4D to avoid problems of fit when the shape parameter is above -1 , in modelling summer extreme rainfall over the Korean peninsula via L-moments estimates from 61 gauging stations. They obtained reliable quantile estimates for several return periods, although a study comparing these estimates from the WAD is ongoing. Here we have modelled extreme rainfall in Thailand by the Wakeby distribution and the method of LH-moments. Design values corresponding to various return periods and their confidence intervals have been obtained for annual maximum rainfalls on a day to day basis, and isopluvial maps of the design values have been derived. Based on the $\eta$ values, we conclude that the LH-WAD estimates are better than those obtained using the L-moment WAD for $87.5 \%$ of the chosen stations. Stations experiencing the greatest rainfalls, in southern-east coast Thailand and the Trat station in the eastern part, correspond to the top two return values. Moreover, confidence intervals from the bootstrap resampling technique also largely represent the true values for 24 sample gauge stations. We therefore conclude that our approach can be applied to model extreme rainfall in Thailand, although we do not claim that our method is the best possible and further consideration of skewness family distributions is ongoing.

\section{Acknowledgments}

The authors would like to thank the financial support provided by Mahasarakham University, Thailand.

\section{References}

Busababodhin, P., Siriboon, M., Keawmun, K. 2015. Modeling of Extreme Precipitation in Upper Northeast of Thailand. Burapha Science Journal, 20(1), 1-10. (in Thai)

Busababodhin, P., Seo, Y.A., Park, J.S., Kumphon, B. 2015. LH-moment estimation of Wakeby distribution with hydrology applications. Stochastic Environmental Research and Risk Assessment, 1-11. 
Deka, S., Borah, M., Kakaty, S.C. 2009. Distribution of annual maximum rainfall series of north-east India. European Water, 3-14.

Dunn, P.K. 2001. Bootstrap confidence intervals for predicted rainfall quantiles. International Journal of Climatology, 21(1), 89-94, doi:10.1002/ joc.596.

Huff, F.A., Angel, J.R. 1992. Rainfall frequency atlas of the midwest Illinois State water survey. Bulletin, 71, Chanpaign, IL.

Khamkong, M. 2012. Statistical modeling of annual monthly maximum rainfall in upper northern region of Thailand, Proceeding of International Days of Statistics and Economics, Prague.

Keawmun, K., Busababodhin, P., Budchamruei, P. 2015. Modeling Monthly Precipitation in Central Northeast of Thailand. KKU Science Journal, 43(1), 137-147. (in Thai)

Keawmun, K., Rattanawan, S., Busababodhin, P., Kumphon, B. 2015. Modeling for extreme rainfall in lower Northeastern of Thailand. The Journal of Applied Science, 13(2), 55-65. (in Thai)

Khongthip, R., Khamkong, M., Bookamana, P. 2013. Modeling annual extreme precipitation in upper northern region of Thailand. Burapha Science Journal, 18, 95-104. (in Thai).

Landwehr, J.M., Matalas, N.C., Wallis, J.R. 1980. Quantile estimation with more or less floodlike distribuitoion. Water Resources Research, 16(3), 547-555, doi:10.1029/WR016i003p00547.

Matalas, N.C., Slack, J.R., Wallis, J.R. 1975. Regional skew in search of a parent. Water Resources Research, 11, 815-826, doi:10.1029/WR011i006 p00815.

Oztekin, T. 2007. Wakeby distribution for representing annual extreme and partial duration rainfall series. Meteorological Applications, 14(4), 381-387, doi:10.1002/met.37.

Park, J.S., Jung, H.S., Kim, R.E., OH, J.H. 2001. Modelling summer extreme rainfall over the Korean peninsula using Wakeby distribution. Internaltional Journal of Climatology, 21(11), 1371-1384, doi:10.1002/joc.701.

Press, W.H., Teukolsky, S.A., Vetterling, W.T., Flannery, B.P. 1996. Numerical Recipes in Fortran 77.

The Art of Scientific Computing (2nd edn). Cambridge University Press: New York.

Rahman, A., Zaman, M.A., Haddad, K., Adlouni, S.E., Zhang, C. 2015. Applicability of Wakeby distribution in flood frequency analysis: a case study for eastern Australia. Hydrological Processes, 29(4), 602-614, doi:10.1002/hyp.10182.

Ross, S.M. 1990. A Course in Simulation. Macmillan Publishing Co: New York.

Seckin, N., Haktanir, T., Yurtal, R. 2011. Flood frequency analysis of Turkey using L-moments method. Hydrological Processes, 25(22), 3499-3505, doi:10.1002/hyp.8077.

Soukissian, T. 2013. Use of multi-parameter distributions for offshore wind speed modeling: The Johnson SB distribution. Applied Energy, 111(0), 982-1000, doi:10.1016/j.apenergy.2013.06.050.

Su, B., Kundzewicz, Z.W., Jiang, T. 2009. Simulation of extreme precipitation over the Yangtze River Basin using Wakeby distribution. Theoretical and Applied Climatology, 96(3-4), 209-219, doi:10.1007/s00704-008-0025-5.

Thai Meteorological Department, 2014. Annual weather summary over Thailand in 2014.

Thai Meteorological Department, 2016. Annual weather summary over Thailand in 2016.

Thai Meteorological Department, 2017. Annual weather summary over Thailand in 2017.

Thai Meteorological Department, 2019. Annual weather summary over Thailand in 2019.

Wang, Q.J. 1997. LH moments of Statistical analysis of extreme events. Water Resources Research, 33, 2841-2848.

Wilks, D.S., McKay, M. 1996. Extreme-value statistics for snowpack water equivalent in the northeastern United States using the cooperative observer network. Journal of Applied Meteorology, 35, 706-713.

Yao, Z., Wei, H., Lui, H., Li, Z. 2013. Statistical vehicle specific power profiling for urban freeways. Procedia - Social and Behavioral Sciences, 96: 2927-2938, doi:10.1016/j.sbspro.2013.08.324.

Zalina, M.D., Desa, M.N.M., Nguyen, V.T.V., Kassim, A.H.M. 2002. Selecting a probability distribution for extreme rainfall series in Malaysia. Water Science and Technology, 45(2),63-68.

http: / / www. tmd. go. th/ programs\% 5Cuploads Varadhan R, 2012 R-package "alabama" constrained nonlinear optimisation. http://cran.r-project.org/web/ packages/alabama/index.html. 